\title{
A SPINAL INJURY CAUSED BY A PATIENT IMPALED ON A SHOTGUN
}

By Glenn G. Reynolds, M.D., J. F. Devery, M.D. and C. J. Scibetta, M.D.

Santa Clara Valley Medical Center, San Fose, California; Watsonville Community Hospital, Watsonville, California

THE patient (B. J.), is a 43-year-old separated male brick-layer, who was in good health until 29 January I974. He lost control of the automobile he was driving and struck a tree. An unloaded nickel-steel Winchester Model I2 full choke, I2 gauge shotgun, carried in the patient's automobile, was driven through the abdomen of the victim (fig. I). The patient was taken by ambulance to the Watsonville Community Hospital, Watsonville, California. On examination in

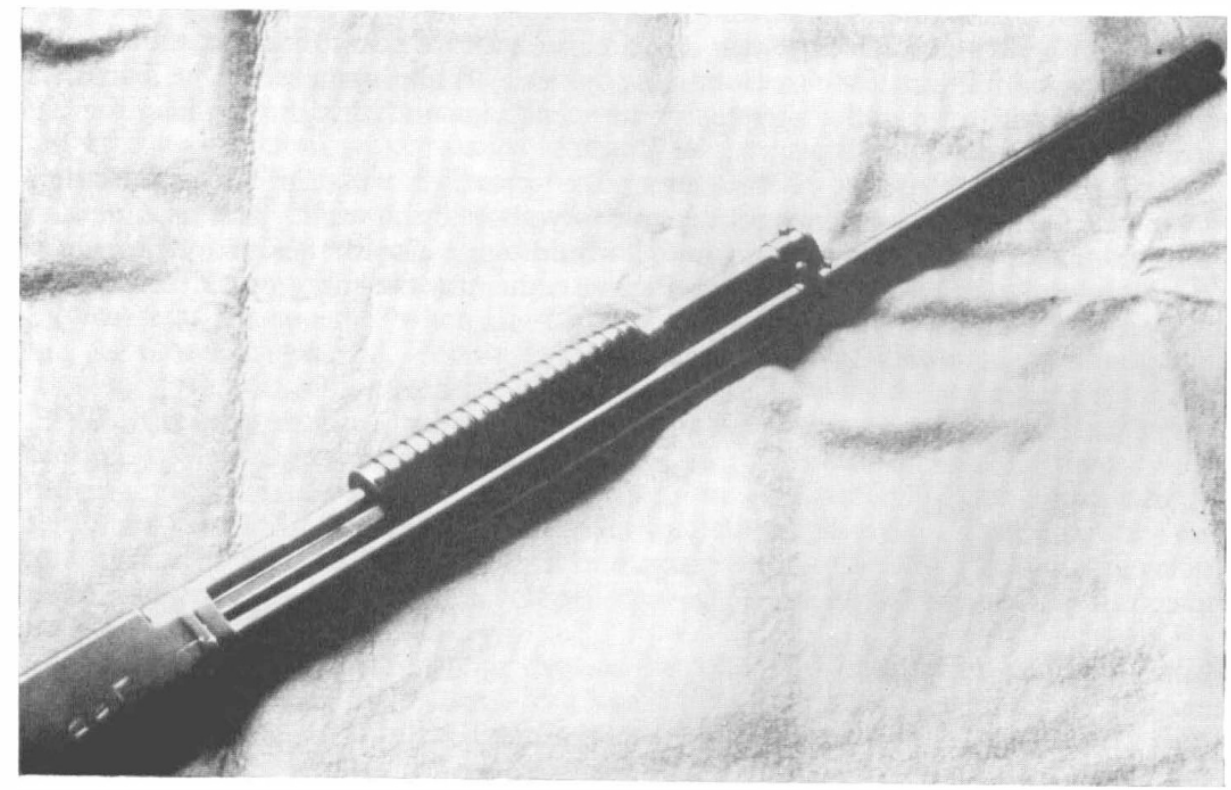

FIG. I

the emergency room by the general surgeon (J. F. D.), it was found that the muzzle had entered the right upper quadrant of the abdomen and was protruding from the left flank, three to four inches posteriorly. The patient was paraplegic with a sensory level of L2 bilaterally. The magazine chamber and stock of the shotgun were protruding anteriorly from the patient's right abdomen. The chamber and stock were partially covered by a green plastic gun carrying case. The distal end of the protruding barrel was plugged with smooth to ragged bone, and attached shredded cloth. 

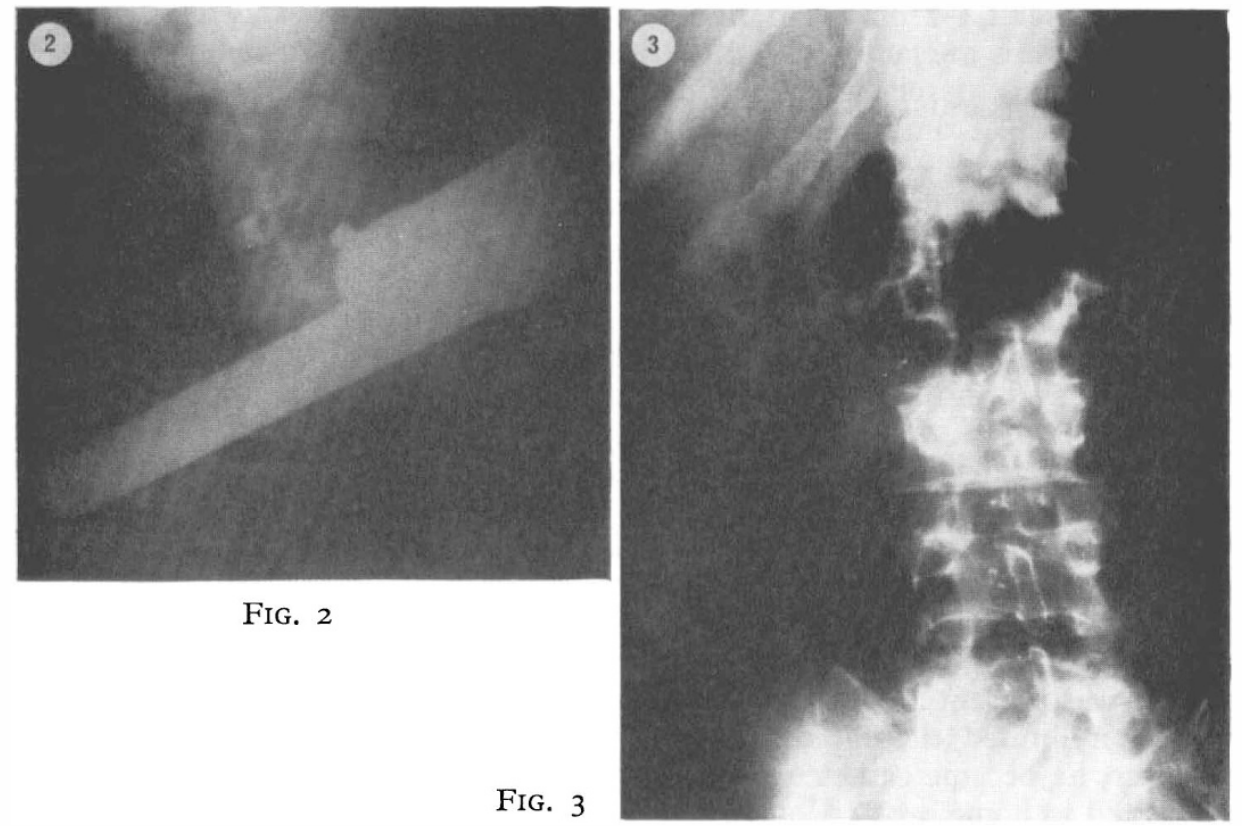

FIG. 3

He was lucid, but in profound shock and had a laceration of the scalp. Blood pressure was restored with two litres of Ringers-lactate and approximately $\mathrm{I}_{2}$ litres of whole blood. Foley catheter was inserted, and urine found to be clear. Levine tube was passed and gastric aspirant was clear.

The patient was taken to the operating room, and intravenous pyelography was done. Since the patient's condition had stabilised, and while waiting the arrival of the neurosurgeon (C. J. S.), X-rays of the spine and abdomen were made. $\mathrm{X}$-rays showed the barrel of the shotgun lying posterior to the vertebral body at $L_{I}$ and L2 with involvement of the left pars interarticularis (figs. 2 and 3 ). There was no extravasation of dye noted in the I.V.P. study. Neurosurgical evaluation confirmed a motor-sensory level at L2 and no sacral sparing. An exploratory laparotomy was performed and the shotgun was removed from the abdomen through the portal of entry. Exploration demonstrated many fine wires present from a previous laparotomy following a stab wound in Baltimore, Maryland, in I968. Old scar and fine wires were removed. Multiple adhesions were present. No blood, gas or intestinal content was present in the abdominal cavity. The path of the gun was found to lie under the right lobe of the liver, passing posteriorly and laterally to the duodenum and passed through the retroperitoneal space. No pancreatic damage was present. The barrel passed posterior to the vena cava, elevating it anteriorly and medially, and entering the vertebral body and it's foramen at LI-2 on the right. There was difficulty in removal of the barrel due to protrusion of the gun sight on the barrel in the surrounding tissues. Appropriate closure was carried out.

The following day, neurosurgical lumbar laminectomy was carried out (by C. J. S.) from Ti2 to L2. This demonstrated that the shotgun barrel had entered 
the foramen at LI-2 on the right side, transfixing the cord and fracturing and rotating outward the lamina of $\mathrm{L}_{\mathrm{I}}$ on the left side. The fragments were removed and surrounding tissues were debrided of bits of cloth. The cord was swollen and a segment of dura was missing, but not repaired, due to the danger of a foreign body in the contaminated wound. The post-operative course was complicated by fever between $\mathrm{IOI}^{\circ}$ and $102^{\circ}$, which was subsequently controlled by Penicillin and Garamycin.

He was transferred to the California Spinal Injury System at Santa Clara Valley Medical Centre on I9 February 1974. At the time of this admission it was noted that all skin wounds were healed. The motor examination demonstrated $\mathrm{L}_{3}$ level on the left and $\mathrm{L}_{1}$ on right. His paralysis has been of the lower motor neuron type, only.

The patient was kept at bed rest until 4 March 1974. Following I.V.P., cystometrogram and urine cultures, his urine became bacteria free and he was started on intermittent catheterisation on 2I February 1974. He subsequently complained of severe burning dysaesthesia of right $\mathrm{LI}_{\mathrm{I}}$ area. On $28 \mathrm{March}$ he started walking with bilateral long leg braces, and was noted to have heterotopic ossification of bone, primarily about the right hip. A $20^{\circ}$ right hip flexion contracture was present at that time. The dysaesthesias and limitation of hip range of motion limited the rapidity of his comprehensive rehabilitation therapies. However, he became catheter free on 29 April I974 and totally independent and discharged to home on Io May I974.

Since discharge, he has remained an out-patient in the Santa Clara Valley Medical Center Spinal Injury Resource Clinic. He has continued to practise ambulation with his braces, but has had severe abdominal and groin pain. He was discharged to out-patient status using:
I. Darvon
2. Parlax
$65 \mathrm{mg}$. q $6 \mathrm{~h}$.
3. Macrodantin $240 \mathrm{mg}$. t. i. d.
4. Ampicillin IOO mg. q. i. d. $\times$ Io days.
5. Carbenecillin $500 \mathrm{mg} . \times 4$ then $250 \mathrm{mg}$. q.i.d.
6. Fe Gluconate 2 q.i.d. $\times$ IO. 5 gr t.i.d.

Significant laboratory findings were as follows:

Hgb: 9.8 g. (9 May 1974)

Alk Phosp: I6I i.u. (20 February 1974) 26I i.u. (20 April I974)

Bone Scintigraph: $5 \cdot 3 \times$ normal

Radioactivity in right hip, as compared with the left hip.

From I4 to I 8 June I974, the patient attended the United States National Wheelchair Games where he assisted the California team with food and social services. He is currently being served by the California State Department of Rehabilitation for vocational guidance and placement as an I.B.M. data technician.

There are several documented cases of penetrating and transfixing wounds which were the source of spinal cord injuries, (see References) but no case history was found in which an impalement wound of this type was described. 


\section{REFERENCES}

Castillo, Rafael \& Khan, Edgar, A. (1950). Asymptomatic transfixion of spinal cord by knife blade. Fournal of Neurosurgery, 7, I79-182.

LIPSCHITZ, ROBERT \& BLOCK, JOSEPH (I962). Stab wounds of the spinal cord. Lancet, I69-I72.

SPENCER, G. T. (I968). Nail-gun accident. British Medical fournal, I, I8I. 